\title{
Physical Properties and Ionic Concentration of the Bovine Cervical Mucus at the Moment of Inseminating: Spontaneous Estrous and Induced Estrous
}

\author{
Bernardi SF ${ }^{1 *}$, Savia $\mathrm{CL}^{2}$, De Paz LJ ${ }^{3}$, Rodriguez $\mathrm{J}^{4}$ and Marini $\mathrm{PR}^{5}$
}

${ }^{1}$ Obstetrics and Pathophysiology of Reproduction, Faculty of Veterinary Science, CIC-Univ Nac Rosario, Latin American Center for Studies of Dairy Problems CLEPL, Casilda, Argentina

${ }^{2}$ Histology II and Special Embryology, Faculty of Veterinary Science, Univ Nac de Rosario, Route 33 and Bv Ov Lakes (2170) Casilda, Santa Fe, Argentina ${ }^{3}$ Binational Center (Argentina-Italy) of Research in Clinical and Applied Cryobiology, Univ Nac of Rosario (CAIC), Casilda, Argentina

${ }^{4}$ Pharmacology and Therapeutics, Faculty of Veterinary Science, Univ Nac De Rosario, Casilda, Argentina

${ }^{5}$ Bovine Production for Milk, Faculty of Veterinary Science, CIC-Univ Nac De Rosario, Casilda, Argentina

*Corresponding author: Bernardi SF, Associate Professor, Obstetrics and Pathophysiology of Reproduction, Faculty of Veterinary Science, CIC-Univ Nac Rosario, Researcher in Latin American Center for Studies of Dairy Problems CLEPL, Route 33 and Bv Ov Lakes (2170) Casilda, Argentina, Tel: +543464423377; Fax: +543464422050; E-mail: sbernard@unr.edu.ar

Rec date: April 28, 2018; Acc date: May 25, 2018; Pub date: May 26, 2018

Copyright: ( 2018 Bernardi SF, et al. This is an open-access article distributed under the terms of the Creative Commons Attribution License, which permits unrestricted use, distribution, and reproduction in any medium, provided the original author and source are credited.

\begin{abstract}
Objective of the investigation was to characterize biochemically the cervical mucus collected prior to the artificial insemination of Holstein heifers comparing spontaneous oestrus with induced oestrus. The concentration of sodium and potassium was determined through flame photometry, chlorine ions by Schoenfeld reaction, magnesium and calcium was determined through colorimetry in micro plates. $\mathrm{pH}$ (reactive tape) and degree of crystallization (optical microscope) were also evaluated. Natural estrous was detected by observing the behavior of the heifers twice a day and by observing the characteristics of the vulva. In order to induce oestrous, an intra vaginal device was placed with $1 \mathrm{gm}$ of progesterone and $2 \mathrm{mg}$ of estradiol benzoate were injected (Day 0). On day 8 the device was withdrawn and $0-150 \mathrm{mg}$ of D-Cloprostenol and $1 \mathrm{mg}$ of Estradiol Cypionate were provided. 56 hours after withdrawal, the device was inseminated and at 60 days of pregnancy determined. The cervical mucus of heifers with spontaneous oestrus showed lower content of sodium and potassium, higher magnesium and chlorine, and bigger proportion of sodium/potassium from that obtained by induce oestrus. When comparing the pregnant with the empty heifers, it was discovered that at the moment of insemination, the $\mathrm{pH}$ value and the degree of crystallization of pregnant heifers was significantly lower, same as the concentrations of potassium and magnesium. Sodium was higher in this group. Pregnancy was always related to high ionic level generating an osmotic force that draws water to the cervical mucus, characteristic fundamental in transport of sperms.
\end{abstract}

Keywords: Heifers; Pregnancy; Ionic electrolytes; Mucus crystallization

\section{Abbreviations}

CM: Cervical mucus; FTAI: Fixed time artificial insemination; SE: Spontaneous estrous; IE: Induced estrous; $\mathrm{mEq} / \mathrm{L}$ : milliequivalent per litre.

\section{Introduction}

The CM plays a fundamental role in the interaction with sperms participating in vital important processes such as sperm motility [1]. The $\mathrm{pH}$ value is relatively easy to take and it is important so as to know the quality of the cervical mucus. This value varies along stages of the cycle, being 6.5-6.8 during estrous and higher when the heifer goes over that stage and gets into the luteal phase of the cycle [2]. This chloride and the potassium are responsible for the crystallization phenomenon; phenomenon that varies between pregnant heifers and empty; and there were also differences when referring to natural estrous or with hormonal manipulations $[3,4]$. The concentration of ionic electrolytes in the CM differs significantly if it is collected from heifers with natural estrous from that when different hormonal games were used to stimulate ovulation in heifers [5]. In milking cows which suffered genetic selection for high milk production, the management of energy is somehow particular, situation which has a negative impact on the reproductive parameters, for example lengthen the period between delivery and next pregnancy [6]. The objective of this work was to determine the content of certain ions (sodium, potassium, calcium, magnesium and chlorine) in the cervical mucus of heifers at the moment of inseminating, comparing estrous detected with a system of FTAI, its relation with the crystallization phenomenon and with reproductive efficiency.

\section{Materials and Methods}

This work was carried out in province of Santa Fe $\left(34^{\circ} 19^{\prime} 31.08^{\prime} \mathrm{S}\right.$, $\left.62^{\circ} 2^{\prime} 18.96^{\prime} \mathrm{W}\right)$ Argentina, during autumn 2015, Center of humid pampas, plain relief with mild and humid climate.

\section{Animals and food}

77 Holstein heifers were used, all of them being in average $25 \pm 2$ months old, and $385 \pm 16 \mathrm{~kg}$ heavy. Animals were fed on: pasture forages (prolific pastures and annual winter greens, oats and ryegrass and summer ones, forage, sorghum and soya), conserved (silages of 
Citation: Bernardi SF, Savia CL, De Paz LJ, Rodriguez J, Marini PR (2018) Physical Properties and lonic Concentration of the Bovine Cervical Mucus at the Moment of Inseminating: Spontaneous Estrous and Induced Estrous. J Vet Sci Technol 9: 545. doi: $10.4172 / 2157-7579.1000545$

Page 2 of 5

whole plants of maize and sorghum, meadow hays) and concentrated (maize and sorghum grains, wheat bran, soya flour and mineral salts).

\section{Detection of natural estrous}

SE was detected by observing the behavior of heifers twice a day (morning and evening) and by observing the vulvar characteristics.

\section{Protocol of IE and insemination}

On day 0 an intra vaginal device was placed with $1 \mathrm{gm}$ of progesterone (DIB Syntex, Luis de Sarro 501, Luis Guillon, Buenos Aires, Argentina) plus an intramuscular injection of $2 \mathrm{mg}$ of estradiol benzoate (Bioestrogen, Biogénesis Bagó, Ruta Pan americana Km 38,500, 1619 Garin, Buenos Aires, Argentina). On day 8 the device was withdrawn and $0-150 \mathrm{mg}$ of $\mathrm{D}$-Cloprostenol (Enzaprost $\mathrm{D}$-C, Biogénesis Bagó) and $1 \mathrm{mg}$ of Estradiol Cypionate was provided in order to synchronize ovulation (Kit Synkro XY, Proagro, Montevideo 5757, S2008DPO Rosario, Santa Fe, Argentina). Insemination (AI) was carried out between 54 and 56 hours after the device was withdrawn.

\section{Confirmation of conception}

Pregnancy was detected by transrectal palpation 60 days after insemination. From that parameter, the heifers were grouped into two reproductive categories: pregnant or conceived or expectant, and empty or non-pregnant.

\section{Collection of the cervical mucus}

The mucus samples were collected immediately before carrying out the artificial insemination and were obtained by vacuuming from the cervix. A $60 \mathrm{ml}$ plastic syringe was used, connected in one extreme to a plastic sheath used for insemination. The sample obtained was aliquoted into 0.5 to $1 \mathrm{~mL}$ samples, stored and properly refrigerated for transportation to the laboratory where they were maintained at a temperature of $-2^{\circ} \mathrm{C}$ till later use.

\section{$\mathrm{pH}$, crystallization and ionic concentration}

$\mathrm{pH}$ was determined through a reactive tape rank 6-7.9 in roll (Macherey-Nagel, Germany, Distribution NORCES: Santa Fe 2873 Rosario. Argentina) and was taken in situ at the moment of the AI. For the crystallization, samples were thawed at room temperature and with a drop of mucus an extended was made for later observation to optical microscope. Crystallization was classified using a 0 to 4 scale, being 0 : no crystal formation; 1 : all crystals have atypical fern leaves; 2 : mainly atypical crystal forms and only some typical, 3 : mostly typical crystals and only some atypical in well-defined fern leaves, 4: all the arborization corresponds to typical crystals [2]. Before determining the ionic content, each sample was homogenized through an automatic processor (Ultra turrax T25 Basic LKA Labortechnik) of 1 per 30 seconds speed. Then samples were centrifuged at $13400 \mathrm{rpm}$ for 5 minutes and the concentration of every ion was expressed in $\mathrm{mEq} / \mathrm{L}$. The concentration of $\mathrm{Na}$ and $\mathrm{K}$ was determined through a flame photometry (Espectofotómetro Zentec ZF 2500). The $\mathrm{Cl}$ was determined through the Schoenfeld reaction (Schoenfeld and Lewellen). Micro plates were used (Plate 96 wells UBOT, CAT \#5530200, Orange Scientific). The $\mathrm{Mg}$ and $\mathrm{Ca}$ were determined through colorimetry in micro plates (Kit Mg-color, Cód. 1580001 and Kit Ca-color, Cód. 1152002, Wiener Laboratories S.A.I.C.). Its reading was carried out with a spectrophotometer (Tecan F50).

\section{Statistical methods}

Each variable was described as its median, maximum and minimum value and / or average and standard error. Comparisons were made between kinds of estrous and within each of them, between reproductive categories of heifers. It was also proved whether there were significant differences among pregnant heifers comparing kinds of estrous and the same procedure was repeated within the empty cows. In all cases the t-student test and the non-parametric (average test) was carried out. In order to show whether there was a relation between the physical phenomenon of crystallization and the cervix secretion as regards ionic concentration, the simple correlation coefficients between the degree of arborization and the content of each ion is estimated. All the analysis above mentioned were carried out through JMP software, in its 5.0 version for Windows (JMP ${ }^{\circ}$, SAS Institute, 2003).

\section{Results}

Table 1 shows the results obtained from the statistical analysis carried out on the heifers grouped according to kind of estrous for each variable under study.

\begin{tabular}{|c|c|c|c|}
\hline \multirow[t]{2}{*}{ S.no } & \multirow[t]{2}{*}{ Chemicals } & Spontaneous estrous & Induced estrous \\
\hline & & \multicolumn{2}{|c|}{ Mna (Max-Min) $X \pm S D$} \\
\hline 1 & $\mathrm{pH}$ & $\begin{array}{lll}7.0(7.4-6.3) & 6.83 \quad \pm \\
0.37^{a} & \end{array}$ & $\begin{array}{lll}7.0(8.0-6.3) & 7.05 & \pm \\
0.41^{a} & \end{array}$ \\
\hline 2 & $\mathrm{GC}_{\mathrm{rz}}$ & $1.5^{\star}(1-3) 1.73 \pm 0.68^{a}$ & $2^{*}(1.5-3) 2.25 \pm 0.49^{b}$ \\
\hline 3 & $\mathrm{Na}$ & $\begin{array}{l}141^{*}(156-109) 137.80 \\
\pm 11.24^{\mathrm{a}}\end{array}$ & $\begin{array}{l}199^{*}(325-101) 198.84 \pm \\
63.15^{\mathrm{b}}\end{array}$ \\
\hline 4 & $\mathrm{~K}$ & $\begin{array}{l}8.8^{*}(20.80-5.5) 10.19 \\
\pm 4.26^{\mathrm{a}}\end{array}$ & $\begin{array}{l}17.95^{*}(98.1-5.2) 23.20 \\
\pm 18.96^{\mathrm{b}}\end{array}$ \\
\hline 5 & $\mathrm{Ca}$ & $\begin{array}{l}2.90 \\
1.65^{\mathrm{a}}\end{array}(5.7-0.7) 2.98 \pm$ & $\begin{array}{ll}2.50 & (7.0-0.3) 2.89 \quad \pm \\
1.57^{\mathrm{a}} & \end{array}$ \\
\hline 6 & $\mathrm{Mg}$ & $\begin{array}{l}3.20^{*}(4.8-2.4) 3.37 \pm \\
0.74^{\mathrm{a}}\end{array}$ & 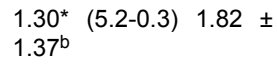 \\
\hline 7 & $\mathrm{Cl}$ & $\begin{array}{l}198^{*}(290-134) 194.08 \\
\pm 27.23^{a}\end{array}$ & $\begin{array}{l}136^{*}(187-93) 134.85 \pm \\
44.83^{\mathrm{b}}\end{array}$ \\
\hline 8 & $\mathrm{Na}: \mathrm{K}$ & $\begin{array}{l}16.71^{*}(23.82-5.24) \\
15.49 \pm 5.29^{a}\end{array}$ & $\begin{array}{l}11.08^{*} \quad(28.79-1.98) \\
11.99 \pm 6.18^{\mathrm{b}}\end{array}$ \\
\hline
\end{tabular}

Table 1: Ionic content of the heifer's cervical mucus according to kind of estrous. Ionic values expressed in $\mathrm{mEq} / \mathrm{L}$-miliequivalent per litre, GC-crystallization degree, Mna (Mx-Mn)-median (maximun valueminimun value); $\mathrm{X} \pm \mathrm{SD}$-average and standard error. ${ }^{\mathrm{a}, \mathrm{b}}$ Different letters assigned in each column indicate statistically significant differences; $\mathrm{P}<0.05$. ${ }^{*}$ Indicate statistically significant differences, median test; $\mathrm{P}<0.001$.

The percentage of heifers achieving pregnancy was $52 \%$ for detected estrous and $50 \%$ for AI, showing no significant differences between both groups. After touching, the animals were grouped according to their reproductive status. Table 2 compares pregnant and nonpregnant females according to the type of estrous. 
Citation: Bernardi SF, Savia CL, De Paz LJ, Rodriguez J, Marini PR (2018) Physical Properties and lonic Concentration of the Bovine Cervical Mucus at the Moment of Inseminating: Spontaneous Estrous and Induced Estrous. J Vet Sci Technol 9: 545. doi: $10.4172 / 2157-7579.1000545$

Page 3 of 5

\begin{tabular}{|c|c|c|c|c|c|c|c|c|}
\hline \multicolumn{2}{|r|}{ EE/EI } & $\mathrm{pH}$ & GC & $\mathrm{Na}(\mathrm{mEQ} / \mathrm{ml})$ & $\mathrm{K}(\mathrm{mEQ} / \mathrm{ml})$ & $\mathrm{Ca}(\mathrm{mEQ} / \mathrm{ml})$ & $\mathrm{Mg}(\mathrm{mEQ} / \mathrm{ml})$ & $\mathrm{Cl}(\mathrm{mEQ} / \mathrm{ml})$ \\
\hline EE & Pregnant & $\begin{array}{ll}6.47 & \pm \\
0.11^{\mathrm{a}} & \end{array}$ & $2.01 \pm 0.26^{a}$ & $140.62 \pm 9.62^{a}$ & $7.76 \pm 1.15^{\mathrm{a}}$ & $2.30 \pm 1.30^{\mathrm{a}}$ & $2.80 \pm 0.27^{a}$ & $189.14 \pm 25.84^{a}$ \\
\hline & Non-pregnant & $\begin{array}{ll}7.15 & \pm \\
0.14^{b} & \end{array}$ & $2.71 \pm 0.70^{b}$ & $134.57 \pm 12.82^{b}$ & $12.97 \pm 4.89^{\mathrm{b}}$ & $3.77 \pm 1.77^{\mathrm{a}}$ & $3.93 \pm 0.60^{\mathrm{b}}$ & $199.83 \pm 30.08^{a}$ \\
\hline $\mathrm{EI}$ & Pregnant & $\begin{array}{ll}6.80 & \pm \\
0.22^{\mathrm{a}} & \end{array}$ & $1.82 \pm 0.22^{\mathrm{a}}$ & $217.84 \pm 69.13^{a}$ & $17.43 \pm 11.10^{a}$ & $2.30 \pm 1.30^{\mathrm{a}}$ & $1.67 \pm 1.41^{a}$ & $137.19 \pm 47.25^{a}$ \\
\hline & Non-pregnant & $\begin{array}{ll}7.50 & \pm \\
0.27^{\mathrm{b}} & \end{array}$ & $2.50 \pm 0.43^{b}$ & $179.84 \pm 50.84^{b}$ & $28.98 \pm 23.21^{\mathrm{b}}$ & $3.08 \pm 1.54^{\mathrm{a}}$ & $1.99 \pm 1.34^{b}$ & $131.45 \pm 42.52^{\mathrm{a}}$ \\
\hline
\end{tabular}

Table 2: Physicochemical properties and ionic content of the heifer's cervical mucus according to their kind of estrous and their reproductive state (median and standard error). EE-Espontaneous ooestrous/detected ooestrous; EI-Induced ooestrous/IATF; Eq/L-miliequivalent per litre; a, b columns with different superscripts are significantly different; $\mathrm{P}<0.05 \mathrm{t}=1.99962$.

Table 3 shows the results obtained when comparing SE with IE within each reproductive category (pregnant and non-pregnant). The coefficient of relation between degree of crystallization and ionic

concentration studied in this work appear in Table 4, differentiating kind of estrous and reproductive category of the heifer.

\begin{tabular}{|l|l|l|l|l|l|l|l|l|}
\hline \multicolumn{2}{|l|}{ Pregnant/Non pregnant } & $\mathbf{p H}$ & $\mathbf{G C}$ & $\mathbf{N a}(\mathbf{m E q} / \mathbf{L})$ & $\mathbf{K}(\mathrm{mEq} / \mathbf{L})$ & $\mathbf{C a}(\mathbf{m E q} / \mathbf{L})$ & $\mathbf{M g}(\mathrm{mEq} / \mathbf{L})$ & $\mathbf{C l}(\mathrm{mEq} / \mathbf{L})$ \\
\hline \multirow{2}{*}{ Pregnant } & EE & $6.47 \pm 0.11^{\mathrm{a}}$ & $2.01 \pm 0.26^{\mathrm{a}}$ & $140.62 \pm 9.62^{\mathrm{a}}$ & $7.76 \pm 1.15^{\mathrm{a}}$ & $2.30 \pm 1.30^{\mathrm{a}}$ & $2.80 \pm 0.27^{\mathrm{a}}$ & $189.14 \pm 25.84^{\mathrm{a}}$ \\
\cline { 2 - 9 } & EI & $6.80 \pm 0.22^{\mathrm{b}}$ & $1.82 \pm 0.22^{\mathrm{a}}$ & $217.84 \pm 69.13^{\mathrm{b}}$ & $17.43 \pm 11.10^{\mathrm{b}}$ & $3.08 \pm 1.54^{\mathrm{a}}$ & $1.67 \pm 1.41^{\mathrm{a}}$ & $137.19 \pm 21.70^{\mathrm{b}}$ \\
\hline \multirow{2}{*}{ Non pregnant } & EE & $7.15 \pm 0.14^{\mathrm{a}}$ & $2.71 \pm 0.70^{\mathrm{a}}$ & $134.57 \pm 12.82^{\mathrm{a}}$ & $12.97 \pm 4.89^{\mathrm{a}}$ & $3.77 \pm 1.77^{\mathrm{a}}$ & $3.93 \pm 0.60^{\mathrm{a}}$ & $199.83 \pm 12.28^{\mathrm{a}}$ \\
\cline { 2 - 9 } & EI & $7.50 \pm 0.27^{\mathrm{b}}$ & $2.50 \pm 0.43^{\mathrm{a}}$ & $179.84 \pm 50.84^{\mathrm{b}}$ & $28.98 \pm 23.21^{\mathrm{a}}$ & $2.44 \pm 1.63^{\mathrm{a}}$ & $1.99 \pm 1.34^{\mathrm{b}}$ & $131.45 \pm 8.68^{\mathrm{b}}$ \\
\hline
\end{tabular}

Table 3: Physicochemical properties and ionic content of the heifers cervical mucus according to their reproductive state and kind of estrous (Median and standard error). EE-spontaneous ooestrous/detected ooestrous; EI-induced ooestrous/IATF; mEq/L-milli equivalent per litre; $\mathrm{a}, \mathrm{b}$ columns with different superscripts are significantly different; $\mathrm{P}<0.05 \mathrm{t}=1.99962$.

\begin{tabular}{|l|l|l|l|l|l|l|}
\hline \multicolumn{2}{|c|}{ EE/EI } & GC/Na & GC/K & GC/Ca & GC/Mg & GC/CI \\
\hline \multirow{2}{*}{ EE } & Pregnant & -0.16 & 0.25 & $0.78^{*}$ & 0.26 & $0.61^{*}$ \\
\cline { 2 - 7 } & Non Pregnant & -0.07 & -0.14 & $0.88^{*}$ & $0.65^{*}$ & 0.33 \\
\hline \multirow{2}{*}{ EI } & Pregnant & 0.03 & 0.12 & -0.39 & 0.41 & $0.16^{*}$ \\
\cline { 2 - 7 } & Non Pregnant & 0 & 0.75 & 0.67 & $0.88^{*}$ & -0.09 \\
\hline
\end{tabular}

and the units in which they were expressed [5]. However, the results obtained are original as regards the category of the cow (heifers), comparison of the kind of service (spontaneous and induced estrous) and the reproductive state 60 days after insemination (pregnant and non-pregnant).

The reproductive result achieved coincides with assertions from other investigators who used similar protocols to FTAI, where the value of registered pregnancy (EE 52\%, EI 50\%), is within the rank cited in the bibliography which goes from $43.3 \%$ a $62.7 \%$ [7-10] and below normal values for EE 64\% [11].

Table 4: Coefficients of simple correlation between degree crystallization and ions. EI-induced ooestrous / detected ooestrous; EIinduced ooestrous/IATF; GC-degree of crystallization; *Statistically significant value.

The relation between Na:K was calculated in the cervical mucus, noticing that such a relation had a similar performance within each estrous, getting significantly higher values when referring to pregnant heifers rather than non-pregnant ones $(\mathrm{P}<0.05)$. On the other side, when comparing the methodology of estrous in each category, it could be observed that the values were always higher when referring to SE $(\mathrm{P}<0.05)$ (Table 5).

\section{Discussion}

The ionic concentration in the cervical mucus of the animals used for this investigation cannot be compared to the results of previous work due to the differences in the methods used for the determinations

The $\mathrm{pH}$ value of the cervical mucus showed no difference between that collected from heifers with spontaneous or induced estrous. In the heifers characterized as pregnant 60 days after insemination, the $\mathrm{pH}$ of the discharge was always lower than that obtained from the nonpregnant ones. These differences coincide with previous work where it was shown that at the beginning of the estrous, the $\mathrm{pH}$ value of the mucus decreased below 7 and the minimum value was measured just before ovulation. Besides the $\mathrm{pH}$ of the cervical mucus of nonpregnant heifers kept stable and with values near the upper limit of the normal variation detected (over 7) [12]. On the other side, when super ovulated cows are being investigated and after at least one ovulation has been noted, the value of the $\mathrm{pH}$ decreased 8 hours after the initiation of the estrous and then gradually increased till recovering initial values. When there was no ovulation, the values of $\mathrm{pH}$ decreased 16 hours afterwards and kept low levels [2]. Pregnant and non- 
Citation: Bernardi SF, Savia CL, De Paz LJ, Rodriguez J, Marini PR (2018) Physical Properties and lonic Concentration of the Bovine Cervical Mucus at the Moment of Inseminating: Spontaneous Estrous and Induced Estrous. J Vet Sci Technol 9: 545. doi: $10.4172 / 2157-7579.1000545$

Page 4 of 5

pregnant heifers, showed values of $\mathrm{pH}$ in the $\mathrm{MC}$ a bit higher when using exogenous hormones in order to stimulate ovulation, situation which can be explained due to an increase in the peroxidase activity. Peroxidase is an important secretory protein, whose synthesis of the uterine epithelium and its oxidative activity is regulated by estrogens; therefore, it could be stated that different levels of estrogens alter the peroxidase activity and that has an impact on the value of the $\mathrm{pH}$ of the cervical discharge.

\begin{tabular}{|c|c|c|c|}
\hline $\begin{array}{l}\mathrm{EE} / \\
\mathrm{EI}\end{array}$ & & Pregnant & Non-Pregnant \\
\hline \multirow[t]{3}{*}{ EE } & Histogram & 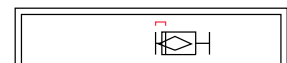 & $1 \neq$ \\
\hline & & $\begin{array}{llllllll} & 1 & 10 & 15 & 20 & 25 & 30\end{array}$ & $\begin{array}{lllllll}0 & 5 & 10 & 15 & 20 & 25 & 30\end{array}$ \\
\hline & $\begin{array}{l}\text { Median } \\
\text { (Max-Min) } \\
X \pm S D\end{array}$ & $\begin{array}{l}17.28^{*}(22.58-16.14) \\
18.40+2.43^{a}\end{array}$ & $\begin{array}{l}10.76^{*}(23.82-5.24) \\
12.16+5.86^{b}\end{array}$ \\
\hline \multirow[t]{3}{*}{$\mathrm{El}$} & Histogram & $\longmapsto$ & \\
\hline & & $\begin{array}{lllllll}0 & 5 & 10 & 15 & 20 & 25 & 30\end{array}$ & 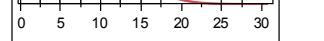 \\
\hline & $\begin{array}{l}\text { Median } \\
\text { (Max-Min) } \\
X \pm S D\end{array}$ & $\begin{array}{l}13.55^{\#}(26.80-5.56) \\
15.04+5.71^{\mathrm{c}}\end{array}$ & $8.83^{\#}(21.98-1.97) 8.94+5.09^{d}$ \\
\hline
\end{tabular}

Table 5: Differences between groups in the relation sodium- potassium $(\mathrm{Na}: \mathrm{K}) .{ }^{\mathrm{a}, \mathrm{b}}$ Lines with different superscripts are significantly different; $\mathrm{P}<0.05$ t 2.16037 . * Lines indicate statistically significant differences; Median test; $\mathrm{P}<0.05$. ${ }^{c, d}$ Lines with different superscripts are significantly different; $\mathrm{P}<0.01$. ${ }^{\#}$ Lines indicate statistically significant differences; Median test; $\mathrm{P}<0.001$.

The mucus collected from the heifers which had reproductive success during insemination crystallized with a lower index when compared to those which did not get pregnant showing generally a similar proportion of arrangements and crystals which correspond to typical and atypical fern leaves. These results coincide with other investigations, reporting also the existence of a negative correlation between estrogen $17 \beta$ and the degree of crystallization of the MCB; and a positive correlation between P4 and crystallization [4,12-14]. In cows where the ovulation process was confirmed, the degree of crystallization decreased 16 hours after the detection of the initiation of the estrous and was kept low till 24 hours after that initiation and the crystallization peak was observed 4 hours after the decrease of the estrogens. When ovulation took place, crystallization showed a higher degree during all the period under study [2]. Based on these investigations, the alkaline $\mathrm{pH}$ found in the mucus of the heifers which did not get pregnant, could be related to the lack of ovulation or otherwise, the process of ovulation took place before the IA day.

Nucleation is the phenomenon which permits the growth of the crystal arrangements; the cervix mucus is characterized as a secretion which can crystallize due to the presence of several organic components such as mucins and salt-shaped electrolytes, or chlorides such as $\mathrm{NaCl}, \mathrm{KCl}$ and $\mathrm{CaCL}$ which provide ionic strength [14]. However, in this work we did not find any correlation between the degree of crystallization and the ionic concentration that was measured.

The low reproductive efficiency is the result of the interaction among several factors; however, most of the reproductive problems appear both at a cellular level and at the body liquid or fluids since several electrolytes are key to the metabolic cycles which are fundamental so that the reproductive dynamic is not affected. In the $\mathrm{MC}$ of the heifers which did not get pregnancy, the concentration of $\mathrm{Na}$ was lower while $\mathrm{K}$ was significantly higher when establishing comparisons with the levels of the mucus collected from pregnant heifers; besides, these levels were reflected in a lower relation $\mathrm{Na}: \mathrm{K} . \mathrm{Na}$ is one of the main cations of the extracellular space, this anion is involved in the hydric balance of the organism and in the mechanics of fluids, regulating in that way the quantity of water and the osmotic pressure [15].

The intracellular relation $\mathrm{K}: \mathrm{Na}$ for optimal performance is between 10-15:1 [15], this same proportion or a little bigger can be expected for the relation $\mathrm{Na}: \mathrm{K}$ in the extracellular zone. From the reproductive point of view, when decreasing the levels of $\mathrm{Na}$ in the organism, de $\mathrm{K}$ levels increase and alter the balance of the relation between both anions. Any imbalance in the relation $\mathrm{Na}: \mathrm{K}$ will indirectly affect the estrous cycle due to a decrease in the capacity to maintain hydric regulation, an indispensable process during the secretions which have to come with the estrous manifestations. On the other side, if the MC levels commented in this work would let us infer that this situation is repeated with other extracellular fluids, then it might be possible to claim that in those heifers which did not get pregnant, this ionic imbalance could be partly responsible for instance provoking alterations in the conduction of the nervous stimulus, which would interfere with the manifestation of estrous and its expression. The previous rise of estrogens responsible for the estrous, demands a delicate nervous adecuation, should that fail, it will negatively affect the advent and normal course of each phase of the estrous cycle.

Magnesium can play an important role in the sperm motility and its ability to fertilize, acting as an antagonist of the intracellular calcium. As far as the anion $\mathrm{Ca}$ is concerned, it becomes a crucial factor in the acrosomic reaction of mammal spermatozoa. In our results, higher numbers for the concentration of $\mathrm{Mg}$ in $\mathrm{MC}$ were associated to heifers which did not get pregnant and the levels of CA were similar to those found in the mucus collected from pregnant heifers; which leads us to claim that these ions did not affect negatively the function of the cervical mucus in the selection of the most suitable spermatozoa and as a means where the sperm has to make its way to reach the fertilization place [14]. What has been said coincides with other investigations which when adding calcium chloride to washed human spermatozoa, had no important effect on the progressive motility, which implies that these cells have specific mechanisms which let them keep an appropriate level of ionized calcium, necessary for normal motility, independent of the external fluctuations at the level of calcium which might come up.

This work proves that in heifers the functionality of the reproductive system and their fertility has been affected, even when considering heifers which did not have a high productive demand to keep high levels of milk production as could be the case of cows.

This means that there are several factors other than a negative energetic balance which affect or modify fertility, such as the level of 
Citation: Bernardi SF, Savia CL, De Paz LJ, Rodriguez J, Marini PR (2018) Physical Properties and lonic Concentration of the Bovine Cervical Mucus at the Moment of Inseminating: Spontaneous Estrous and Induced Estrous. J Vet Sci Technol 9: 545. doi: $10.4172 / 2157-7579.1000545$

Page 5 of 5

hormones and circulating metabolites or the nervous interactions of the brain with the hypothalamus and the pituitary. Mechanisms which need deepening since they influence the transcriptional expression or activity of the coding genes of the different mucins which take part in the secretion of the cervical mucus, controlling in that way the volume or quantity of the synthesis and its consequent secretion.

\section{Acknowledgement}

The authors express their thanks to M.V. Bruno Cieslowski for providing the animals and for his collaboration in different tasks. To the Lab Wiener SAIC, Rosario, Santa Fe, Argentina for providing the necessary equipment for the determination of magnesium and calcium. To the Secretary of State, Science, Technology and Innovation of the Province of Santa Fe, Argentina, for the granted subsidy which let us finance part of this work.

\section{References}

1. Richardson L, Hanrahan JP, O'Hara L, Donovan A, Fair S (2011) Ewe breed differences in fertility after cervical AI with frozen-thawed semen and associated differences in sperm penetration and physicochemical properties of cervical mucus. Anim Reprod Sci 129: 37-43.

2. Tsiligianni T, Amiridis GS, Dovolou E, Meneegatos I, Chadio S (2011) Association between physical properties of cervical mucus and ovulation rate in superovulated cows. Can J Vet Res 75: 248-253.

3. Verma KK, Prasad S, Kumaresan A, Mohanty TK, Layek SS, et al. (2014) Characterization of physico-chemical properties of cervical mucus in relation to parity and conception rate in Murrah buffaloes. Veterinary World 7: 467-471.

4. Bernardi S, Rinaudo A, Marini P (2016) Cervical mucus characteristics and hormonal status at insemination of Holstein cows. Iran J Vet Res 17: 45-49.

5. Tsiligianni T, Karagiannidis A, Roubies N, Saratsis P, Brikas P (2002) Concentration of calcium, zinc, magnesium, potassium and sodium in the bovine cervical mucus during normal oestrous and oestrous induced by progesterone and/or PGF2 $\alpha$. Reprod Fertil Dev 14: 427-431.

6. Matiller V, Díaz PU, Stangaferro ML, Rodriguez FM, Ortega HH, et al. (2014) Role of transforming growth factor B superfamily in ovarian and its relation to the pathogenesis of bovine cystic ovarian disease. Revista FAVE 13: 7-20.

7. Cutaia LE, Peres LC, Pincinato D, Chesta P, Ramos M, et al. (2007) Meat heifer synchronization programs in beef heifers: critical points to consider. VII International Symposium on Animal Reproduction, Córdoba, Argentina, pp: 83-104.

8. Chesta P, Filippi L, Ramos M (2009) Evaluation of pregnancy rates in fixed-time Artificial Insemination (IATF) protocols using different doses of estradiol cypionate in heifers. Proc Annu VII Symp Intern Reprod Anim, Córdoba, Argentina.

9. Sales JN, Carvalho JB, Crepaldi GA, Cipriano RS, Jacomini JO, et al. (2012) Effects of Two estradiol esters (benzoate and cypionate) on the induction of synchronized ovulations in Bos indicus cows submitted to a timed artificial insemination protocol. Theriogenology 78: 510-516.

10. Callejas S, Uslenghi G, Catalano R, Larghi J, Cabodevila J (2014) Comparison of two protocols to synchronize ovulation and implement artificial insemination in heifers. Rev Vet 25: 100-104.

11. Castro Cruz JA (2013) Percentages of pregnancy and times of artificial insemination in cows criollas $\mathrm{x}$ norman in the municipality of Ciénega, Boyacá. Agricultural Connection JDC 3: 19-27.

12. Sharma HC, Dhami AJ, Kavani FS (2011) Properties of estrual cervical mucus in relation to plasma progesterone and conception rates in buffaloes. Ind J Anim Reprod 32: 8-11.

13. Layek SS, Mohanty TK, Kumaresan A, Behera K, Chand S (2013) Cervical mucus characteristics and periestrual hormone concentration in relation to ovulation time in Zebu (Sahiwal) cattle. Livest Sci 152: 273-281.

14. Cortés ME, González F, Vigil P (2014) Crystallization of Bovine Cervical Mucus at Oestrus: An Update. Rev Med Vet 28: 103-116.

15. Campos GR, Hernández EA (2008) Nutrition/Fertility Relationship in Bovines. Faculty of Agricultural Sciences, Department of Animal Science, National University of Colombia, Palmira Headquarters. 